\title{
Tingkat Korosivitas Air Terhadap Infrastruktur Sumber Daya Air Berbahan Semen atau Mortar dengan fc' $\leq 30$ MPa pada 9 Waduk di Indonesia
}

\author{
Devita Satya Lestari *
}

Balai Hidrologi dan Lingkungan Keairan, Direktorat Bina Teknik SDA, Jalan Ir. H. Juanda Nomor 193, Bandung, 40135, Indonesia

*e-mail: devianastasia.dd@gmail.com; devita.lestari@pu.go.id

\begin{abstract}
Abstrak. Korosi atau kerusakan yang terjadi di infrastruktur sumber daya air terutama yang berbahan semen atau mortar dengan $f_{c}$ ' atau dengan nilai kuat tekan $\leq 30 \mathrm{Mpa}$, dapat menimbulkan banyak kerugian. Kerugian yang ditimbulkan antara lain kerugian secara materiil karena korosi menggerogoti semua aset infrastruktur dan tentunya kerugian dalam hal keamanan karena dapat mengancam keselamatan manusia. Korosi merupakan permasalahan yang sangat penting dan tidak akan ada habisnya, karena peristiwa korosi terjadi secara terus-menerus dan berkelanjutan. Peristiwa korosi tidak dapat terjadi dengan sendirinya, tetapi karena adanya berbagai faktor-faktor tertentu yang dapat menyebabkan terjadinya korosi. Tujuan dari studi ini adalah untuk menentukan tingkat korosivitas air terhadap infrastruktur sumber daya air berbahan semen atau mortar dengan fc' atau dengan nilai kuat tekan $\leq 30$ MPa pada 9 waduk di Indonesia, sehingga akan diketahui rekomendasi yang tepat untuk pencegahan dan pengendalian korosivitas air terhadap infrastruktur sumber daya air berbahan semen atau mortar dengan fc' atau dengan nilai kuat tekan $\leq 30$ $\mathrm{MPa}$, karena semen merupakan salah satu material yang paling banyak digunakan saat ini. Studi ini menggunakan data-data primer kualitas air. Metode pengambilan, penyimpanan, dan pengawetan sampel air dilakukan dengan mengikuti ketentuan dari Standar Nasional Indonesia Nomor 6989.57:2008. Pengujian kualitas air dilakukan oleh laboratorium yang terakreditasi. Metode perhitungan menggunakan rumus Langelier Saturation Index (LSI) A, B, C, D, dan rumus Saturation Index (SI) dari Standard Method APHA-AWWA-WEF. Hasil perhitungan LSI A, B, C, D, dan SI Standard Method APHA-AWWA-WEF menunjukkan bahwa tingkat korosivitas air di 9 waduk berpotensi menyebabkan korosi terhadap infrastruktur sumber daya air berbahan semen atau mortar dengan $f_{c}$ ' atau dengan nilai kuat tekan $\leq$ $30 \mathrm{MPa}$.
\end{abstract}

Kata kunci: infrastruktur sumber daya air, Langelier Saturation Index, Saturation Index, tingkat korosivitas air.

Abstract. Water Corrosivity Level Againts the Water Resources Infrastructure Made of Cement or Mortar with fc' $\leq$ $30 \mathrm{MPa}$ in 9 Reservoirs in Indonesia. Corrosion or damage that occurs in the infrastructure of water resources, especially those made of cement or mortar with $\mathrm{fc}^{\prime}$ or with a compressive strength value of $\leq 30 \mathrm{MPa}$ will be able to engender losses. Losses incurred, in the form of losses materially because of corrosion gnaw off all infrastructure assets and of course in losses terms of security, because it can threaten the safety of a human. Corrosion is a very important problem and will not be endless, as corrosion events occur continuously and sustainably. Corrosion events cannot occur by themselves, but because of certain factors that may cause corrosion. The purpose of this study is to determine the level of water corrosivity to the infrastructure of water resources made from cement or mortar with $f_{c}^{\prime}$ or with a compressive strength value of $\leq 30 \mathrm{MPa}$ in 9 reservoirs in Indonesia, to develop appropriate recommendations for the prevention and control of the water corrosivity to the infrastructure of water resources made from cement or mortar with $f_{c^{\prime}}$ or with a compressive strength value of $\leq 30 \mathrm{MPa}$ because cement is one of the most used materials today. This study uses water quality primary data. The methods of capturing, storing, and preserving water samples are carried out following the provisions of Indonesian national standard number 6989.57:2008. Water quality testing is done by accredited laboratories. The method of calculation uses the Langelier Saturation Index (LSI) A, B, C, D, and the formula Saturation Index (SI) of the Standard Method APHA-AWWA-WEF. Calculation results of LSI A, B, C, D, and SI Standard Method APHA-AWWA-WEF show that the level of water corrosivity in 9 reservoirs has the potential to cause corrosion of water resources infrastructure made of cement or mortar with $f c^{\prime}$ or with a compressive strength value of $\leq 30 \mathrm{MPa}$.

Keywords: Langelier Saturation Index, Saturation Index, water corrosivity level, water resource infrastructure. 


\section{Graphical Abstract}

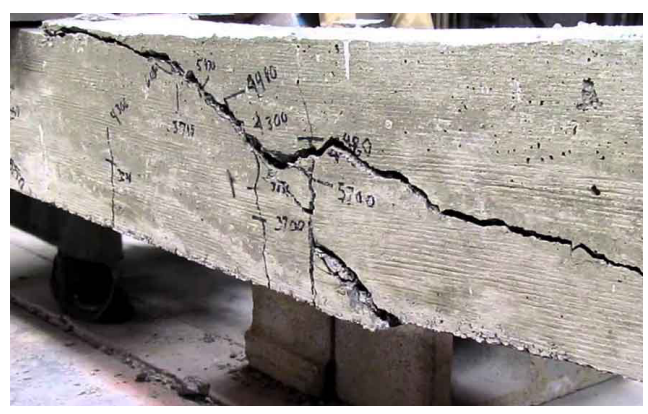

\section{Pendahuluan}

Korosi atau kerusakan yang terjadi pada infrastruktur sumber daya air terutama yang berbahan semen dapat menimbulkan banyak kerugian. Kerugian yang ditimbulkan, antara lain berupa kerugian secara materiil karena korosi menggerogoti semua aset infrastruktur dan tentunya kerugian dalam hal keamanan dan keselamatan manusia. Korosi merupakan permasalahan yang sangat penting dan tidak akan ada habisnya, karena peristiwa korosi terjadi secara terusmenerus dan berkelanjutan. Peristiwa korosi tidak dapat terjadi dengan sendirinya, tetapi dengan adanya berbagai faktor-faktor tertentu yang dapat menyebabkan terjadinya korosi. Selain karena adanya kelembaban udara yang cukup tinggi, paparan gas-gas atmosferik dan bahan kimia, suhu/temperatur, $\mathrm{pH}$, media korosif, faktor bakteri pereduksi padatan terlarut, lingkungan dan organisme (Jalaluddin dkk., 2015), faktor lainnya yang dapat menyebabkan korosi pada infrastruktur sumber daya air, seperti pada bendungan, embung, waduk, bendung, saluran irigasi, saluran drainase, dan saluran air baku, adalah tidak terlepas dari faktor air yang bersifat korosif.

Istilah korosivitas air dapat diartikan sebagai sifat dari suatu bahan, yang dalam hal ini ialah air yang dapat menyebabkan korosi atau karat, sehingga dapat disimpulkan bahwa berbagai pencemaran kualitas air dan pencemaran lingkungan dapat juga menjadi faktor penyebab mengapa air dapat bersifat korosif terhadap berbagai infrastruktur. Air yang bersifat korosif terhadap infrastruktur sumber daya air berbahan semen, dipengaruhi oleh parameter-parameter kualitas air, diantaranya parameter $\mathrm{pH}$, suhu/temperatur, Daya Hantar Listrik (DHL), alkalinitas, padatan terlarut total (TDS), dan parameter kalsium (Lestari dan Moelyo, 2018). Tujuan dari studi ini adalah untuk menentukan tingkat korosivitas air terhadap infrastruktur sumber daya air berbahan semen atau mortar dengan $\mathrm{fc}^{\prime}$ atau dengan nilai kuat tekan $\leq 30 \mathrm{MPa}$, sehingga nantinya akan diketahui rekomendasi yang tepat untuk pencegahan dan pengendalian korosivitas air terhadap infrastruktur sumber daya air berbahan semen atau mortar dengan $\mathrm{fc}^{\prime}$ atau dengan nilai kuat tekan $\leq 30 \mathrm{MPa}$, karena semen merupakan salah satu material yang paling banyak digunakan saat ini. Kebutuhan semen nasional saat ini diperkirakan mencapai 72 juta ton per tahun (Prasetyadi, 2018). Semen juga merupakan salah satu bahan konstruksi paling populer di dunia konstruksi modern. Semen adalah bahan perekat kimia yang memberikan perkerasan terhadap material campuran lainnya menjadi suatu bentuk yang kaku dan tahan lama (Arsitur Studio, 2020).

\section{Metodologi}

Studi ini menggunakan data-data primer, dimana pengujian kualitas airnya dilakukan secara langsung di lapangan maupun di laboratorium. Sampel air diambil, disimpan dan diawetkan sesuai dengan Standar NasionaI Indonesia (SNI) Nomor 6989.57:2008 (Badan Standardisasi Nasional, 2008) dan pengujian kualitas air dilakukan oleh Laboratorium Balai Litbang Lingkungan Keairan yang telah terakreditasi. Studi ini berlokasi di 9 (sembilan) waduk di Indonesia dan dilakukan pada tahun 2018. Metode yang digunakan untuk menghitung tingkat korosivitas air terhadap infrastruktur sumber daya air berbahan semen atau mortar dengan $\mathrm{fc}^{\prime}$ atau dengan nilai kuat tekan $\leq 30 \mathrm{MPa}$ adalah dengan menggunakan rumus Langelier Saturation Index A, B, C, D dari Langelier W.F, 1936 dan Saturation Index (SI) dari Standard Method APHA-AWWA-WEF (Kenny dkk., 2017). Datadata kualitas air yang diperlukan untuk perhitungan tingkat korosivitas air diantaranya adalah data parameter suhu/temperatur $(\mathrm{T}), \mathrm{pH}$, alkalinitas sebagai $\mathrm{CaCO}_{3}$, padatan terlarut total (TDS), kalsium $\left(\mathrm{Ca}^{2+}\right)$, dan Daya Hantar Listrik.

Rumus perhitungan tingkat korosivitas air dengan menggunakan rumus Saturation Index (SI) Standard Method (APHA-AWWA-WEF) (Kenny dkk., 2017), jika parameter-parameter kualitas air yang diujikan tidak lengkap, adalah sebagai berikut:

$$
\begin{aligned}
& \mathrm{E}=308,67 \mathrm{e}^{-0,00457976(\mathrm{~T})} ; \mathrm{T} \text { dalam } \mathrm{K}={ }^{\circ} \mathrm{C}+273,15 \\
& \mathrm{~A}=1,82 \times 10^{6}(\mathrm{ET})^{-1,5}
\end{aligned}
$$

Maka,

$$
\begin{aligned}
p f_{m}= & \mathrm{A}(\sqrt{ } I /[1+\sqrt{ } I]-0,3 I) \\
\mathrm{pK}_{2}= & 107,8871+0,03252849 \mathrm{~T}-(5151,79 / \mathrm{T})- \\
& (\log \mathrm{T} \times 38,92561)+\left(563713,9 / \mathrm{T}^{2}\right)
\end{aligned}
$$

$\mathrm{pK}_{\mathrm{w}}=(4470,99 / \mathrm{T})+0,017060 \mathrm{~T}-6,0875$ 
$\mathrm{pK}_{\mathrm{sc}}=171,9065+0,077993 \mathrm{~T}-(2839,319 / \mathrm{T})-$ $(\log \mathrm{T} \times 71,595)$

$\left[\mathrm{HCO}_{3}{ }^{-}\right]=\left(\mathrm{Alk}_{\mathrm{t}}-\mathrm{Alk}_{0}+10^{[\mathrm{pfm}-\mathrm{pH}]}-10^{[\mathrm{pH}+\mathrm{pfm}-}\right.$ $\left.\mathrm{pKw}^{2}\right) /\left(1+2 \times 10^{[\mathrm{pH}+3 \mathrm{pfm}-\mathrm{pK} 2]}\right)$

$\mathrm{p}\left[\mathrm{HCO}_{3}{ }^{-}\right]=-\log \left[\mathrm{HCO}_{3}{ }^{-}\right]$

$\left[\mathrm{Ca}^{2+}\right]=\left[\mathrm{Ca}_{t}=\mathrm{Ca}_{\mathrm{ip}}\right]$

$\mathrm{p}\left[\mathrm{Ca}^{2+}\right]=-\log \left[\mathrm{Ca}^{2+}\right]$

$\mathrm{pHs}=\mathrm{pK} 2-\mathrm{pKs}+\mathrm{p}\left[\mathrm{Ca}^{2+}\right]+\mathrm{p}\left[\mathrm{HCO}_{3}{ }^{-}\right]+5 p f_{m}$

$\mathrm{SI}=\mathrm{pH}-\mathrm{pHs}$

dengan SI adalah saturation index, $\mathrm{pHs}$ adalah $\mathrm{pH}$ saturasi, dan $\mathrm{pH}$ adalah nilai $\mathrm{pH}$.

Penilaian hasil perhitungan Saturation Index (SI) adalah hasil akhir dari pengukuran korosivitas air terhadap infrastruktur sumber daya air berbahan semen dan penilaian tersebut mengacu pada Tabel 1, sebagai berikut.

Sedangkan jika parameter-parameter yang dianalisis lebih lengkap (Lestari dan Moelyo, 2018), harus menggunakan rumus perhitungan yang berbeda.

Sedangkan rumus perhitungan tingkat korosivitas air dengan menggunakan rumus Langelier Saturation Index (LSI) A, B, C, D Langelier W.F, 1936, adalah sebagai berikut:

$$
\begin{aligned}
& \mathrm{A}=(\log [\mathrm{TDS}]-1) \\
& \mathrm{B}=-13,12 \times \log \left({ }^{\circ} \mathrm{C}+273\right)+34,55 \\
& \mathrm{C}=\log \left[\mathrm{Ca}^{2+} \text { sebagai } \mathrm{CaCO}_{3}\right]-0,4 \\
& \mathrm{D}=\log \left[\text { alkalinitas seabgai } \mathrm{CaCO}_{3}\right] \\
& \mathrm{pHs}=(\mathrm{f}+\mathrm{A}+\mathrm{B})-(\mathrm{C}+\mathrm{D}) \\
& \mathrm{LSI}=\mathrm{pH}-\mathrm{pHs}
\end{aligned}
$$

dengan LSI adalah Langelier Saturation Index, $\mathrm{pH}$ adalah $\mathrm{pH}$ saturasi, dan $\mathrm{pH}$ adalah nilai $\mathrm{pH}$.

Penilaian hasil perhitungan Langelier Saturation Index (LSI) adalah hasil akhir dari pengukuran korosivitas air terhadap infrastruktur sumber daya air berbahan semen dan penilaian tersebut mengacu pada Tabel 2 sebagai berikut.

Tabel 1. Penilaian Saturation Index/SI berdasarkan APHA-AWWA-WEF

\begin{tabular}{cc}
\hline Nilai SI & Keterangan \\
\hline SI $<0$ & berpotensi korosi \\
SI $=0$ & stabil \\
SI $>0$ & berpotensi membentuk kapur/kerak \\
\hline
\end{tabular}

Tabel 2. Penilaian Langelier Saturation Index/LSI A, B, C, D

\begin{tabular}{cc}
\hline Nilai LSI & Keterangan \\
\hline LSI $<0$ & berpotensi korosi \\
LSI $=0$ & stabil \\
LSI $>0$ & berpotensi membentuk kapur/kerak \\
\hline
\end{tabular}

\section{Hasil dan Pembahasan}

Berikut ini adalah data-data kualitas air hasil pengujian di lapangan maupun pengujian di laboratorium untuk perhitungan dengan menggunakan rumus Saturation Index (SI) Standard Method, APHA-AWWAWEF. Data-data terdiri dari parameter suhu, $\mathrm{pH}$, alkalinitas, padatan terlarut total, daya hantar listrik dan parameter kalsium, dapat dilihat pada Tabel 3.

Sedangkan berikut ini adalah data-data kualitas air hasil pengujian di lapangan dan pengujian di laboratorium, yang digunakan untuk menghitung tingkat korosivitas air terhadap infrastruktur sumber daya air berbahan semen dengan menggunakan rumus Langelier Saturation Index A, B, C, D, Langelier, 1936, dapat dilihat pada Tabel 4.

Hasil perhitungan tingkat korosivitas air terhadap infrastruktur sumber daya air berbahan semen atau mortar dengan $\mathrm{fc}^{\prime}$ atau dengan nilai kuat tekan $\leq 30 \mathrm{MPa}$ dengan menggunakan rumus Saturation Index dari Standard Method, APHA-AWWA-WEF, diperoleh hasil bahwa keseluruhan waduk (9 waduk), air waduknya berpotensi menyebabkan korosi atau pelapukan terhadap infrastruktur sumber daya air berbahan semen, hal ini karena $\mathrm{pH}$ air di waduk-waduk tersebut bersifat asam dan basa. Menurut Mulyono (2003), air normal memiliki $\mathrm{pH}$ sekitar 7 (tujuh), sedangkan nilai $\mathrm{pH}$ di atas 7 menyatakan kebasaan dan nilai $\mathrm{pH}$ di bawah 7 menyatakan keasaman. Menurut literatur lainnya, $\mathrm{pH}$ rendah pada air permukaan dapat terjadi secara alami atau karena adanya peningkatan karbon dioksida terlarut dan kurangnya alkalinitas. $\mathrm{pH}$ yang rendah dapat meningkatkan korosi (Chaulk dan Gates, 2019). Proses pembentukan kapur/korosi pada infrastruktur terjadi karena adanya proses karbonasi, yakni reaksi antara karbondioksida $\left(\mathrm{CO}_{2}\right)$ dengan unsur kalsium oksida dalam komposisi kimia semen $(\mathrm{CaO})$, dengan persamaan kimia sebagai berikut:

$\mathrm{CO}_{2}+\mathrm{CaO} \longrightarrow \mathrm{CaCO}_{3}$ (kapur)

Secara lengkapnya korosi pada semen atau mortar terjadi akibat terbentuknya ettringite. Proses terjadinya ettringite disebabkan karena reaksi kimia antara unsur kalsium $\left(\mathrm{Ca}^{2+}\right)$ di dalam semen $(\mathrm{CaO})$ dengan garamgaram sulfat $\left(\mathrm{SO}_{4}{ }^{2-}\right)$ dari air. Sama halnya dengan proses korosi pada logam atau besi, ettringite yang terjadi dapat menyebabkan pengembangan volume dan massa semen atau mortar terdesak. Secara lengkapnya proses hidrasi antara semen $\left(\mathrm{C}_{3} \mathrm{~S}\right.$ dan $\left.\mathrm{C}_{2} \mathrm{~S}\right)$ dengan air menjadi pasta semen $\left(3 \mathrm{CaO} .2 \mathrm{SiO}_{2} .3 \mathrm{H}_{2} \mathrm{O}\right.$, disingkat $\left.\mathrm{CSH}\right)$, dengan persamaan kimia sebagai berikut:

$\mathrm{C}_{3} \mathrm{~S}+\mathrm{H}_{2} \mathrm{O} \longrightarrow \mathrm{CSH}+\mathrm{Ca}(\mathrm{OH})_{2}$ 


$$
\mathrm{C}_{2} \mathrm{~S}+\mathrm{H}_{2} \mathrm{O} \longrightarrow \mathrm{CSH}+\mathrm{Ca}(\mathrm{OH})_{2}
$$

$\mathrm{Ca}(\mathrm{OH})_{2}$ yang terjadi kemudian bereaksi dengan garam-garam sulfat $\left(\mathrm{SO}_{4}{ }^{2-}\right)$ dari air atau tanah:

$$
\mathrm{Ca}(\mathrm{OH})_{2}+\mathrm{MgSO}_{4} \longrightarrow \mathrm{Mg}(\mathrm{OH})_{2}+\mathrm{CaSO}_{4}
$$

$\mathrm{CaSO}_{4}$ yang terjadi bereaksi kembali dengan $\mathrm{C}_{3} \mathrm{~A}$ dari semen dan air menjadi ettringite:

$$
\mathrm{C}_{3} \mathrm{~A}+\mathrm{CaSO}_{4}+\mathrm{H}_{2} \mathrm{O} \longrightarrow \text { Ettringite }
$$

Ettringite memiliki bentuk kristal seperti jarum. Ettringite ini dapat menyebabkan pengembangan volume dan massa semen atau mortar, sehingga dapat membuat semen atau mortar pecah atau terkorosi.

Semen adalah bahan perekat kimia yang memberikan perkerasan terhadap material campuran lainnya menjadi suatu bentuk yang kaku dan tahan lama. Banyak bahan kimia dan mineral yang terkandung dalam bubuk semen, setiap kandungan bahan tertentu mempengaruhi kualitas semen. Bahan semen yang digunakan secara umum terbuat dari kapur $(\mathrm{CaO})$, silika $\left(\mathrm{SiO}_{2}\right)$, alumina $\left(\mathrm{Al}_{2} \mathrm{O}_{3}\right)$, besi oksida $\left(\mathrm{Fe}_{2} \mathrm{O}_{3}\right)$, magnesium oksida $(\mathrm{MgO})$, sulfur trioksida $\left(\mathrm{SO}_{3}\right)$, dan alkali $\left(\mathrm{K}_{2} \mathrm{O}\right)$ dan $\left(\mathrm{Na}_{2} \mathrm{O}\right)$ (Arsitur Studio, 2020).

Menurut literatur lainnya, semen komposisinya terdiri dari kalsium atau batu kapur $\left(\mathrm{CaCO}_{3}\right)$, aluminium oksida $\left(\mathrm{Al}_{2} \mathrm{O}_{3}\right)$, pasir silikat $\left(\mathrm{SiO}_{2}\right)$, bijih besi $\left(\mathrm{Fe}_{2} \mathrm{O}_{3}\right)$ serta senyawa-senyawa lain yang jumlahnya hanya beberapa persen dari jumlah semen, yang terdiri dari: $\mathrm{MgO}, \mathrm{SO}_{3}, \mathrm{~K}_{2} \mathrm{O}, \mathrm{Na}_{2} \mathrm{O}$ (Prasetyadi, Wahid Putra, 2018). Hampir semua larutan kimia terutama sulfat bereaksi dengan kalsium hidroksida, $\mathrm{Ca}(\mathrm{OH})_{2}$ dan trikalsium aluminat $\left(\mathrm{C}_{3} \mathrm{~A}\right)$ dari semen yang berhidrasi untuk membentuk senyawa kalsium sulfat dan kalsium sulfoaluminat. Dalam hal ini, kalsium sulfat dan magnesium sulfat adalah yang paling reaktif dalam suasana basa.

Pencemaran lingkungan yang terjadi di waduk dan sekitar waduk juga menjadi salah satu penyebab mengapa air di waduk-waduk tersebut dapat berpotensi korosi terhadap infrastruktur sumber daya air. Salah satu cara untuk mengantisipasinya adalah dengan mencegah atau tidak membuang limbah, terutama limbah yang mengandung kapur atau $\mathrm{CaCO}_{3}$ (Yousefi, dkk, 2016). Sumber pencemar dapat berasal dari limbah domestik, limbah peternakan atau oleh sumber lain (Susanti, dkk, 2012).

Pada saat bersamaan, peristiwa korosi dipengaruhi oleh beberapa faktor, yakni faktor kimia, fisika, dan faktor biologi. Faktor kimia diantaranya termasuk $\mathrm{pH}$, kesadahan yang rendah, alkalinitas, TDS, dan senyawa lainnya. Sedangkan faktor fisika berupa suhu atau temperatur dan Daya Hantar Listrik (DHL). Peningkatan kemampuan air sehingga menjadi sangat korosif terhadap infrastruktur sumber daya air, dipengaruhi oleh berbagai parameter diantaranya parameter $\mathrm{pH}$, temperatur air, daya hantar listrik yang tinggi, kadar TDS yang tinggi, padatan tersuspensi dan klorin (Sigler dan Bauder, 2009). Penyebab adanya kadar TDS di perairan adalah karena adanya bahan-bahan anorganik berupa ion-ion, dan biasanya disebabkan oleh adanya limbah pembuangan yang berasal dari rumah tangga. TDS mengandung berbagai zat terlarut, baik itu zat organik, anorganik, atau material lainnya, dengan diameter $<10^{-3} \mu \mathrm{m}$, yang terdapat pada sebuah larutan, yang terlarut dalam air (Rinawati dkk., 2016). Perubahan dalam konsentrasi TDS dapat membahayakan karena akan menyebabkan perubahan salinitas, perubahan komposisi ion-ion dan toksisitas masing-masing ion.

Perubahan salinitas dapat mengganggu keseimbangan biota air, biodiversitas, dan menyebabkan toksisitas yang tinggi pada tahapan hidup organisme (Rinawati dkk, 2016). Perubahan salinitas juga dapat menyebabkan adanya perubahan tingkat korosivitas di dalam air. Kemudian selain pengaruh antropogenik berupa limbah domestik dan industri, nilai TDS di perairan sangat dipengaruhi oleh pelapukan batuan dan limpasan dari tanah (Aribiyanto, 2016).

Besarnya nilai DHL (Daya Hantar Listrik) bergantung dari ion-ion anorganik, valensi, dan suhu/temperatur. Besarnya Daya Hantar Listrik (DHL) bergantung pada kandungan ion anorganik atau TDS. Sedangkan parameter kalsium merupakan penyebab utama kesadahan air, selain kalsium ada pula parameter magnesium. Pada perairan yang sadah, kandungan kalsium, magnesium, karbonat, dan sulfat biasanya tinggi (Effendi, 2003). Jika dipanaskan, perairan sadah akan membentuk kerak.

Tabel 3. Data kualitas air untuk perhitungan tingkat korosivitas air terhadap infrastruktur sumber daya air berbahan semen menggunakan rumus SI, Standard Method, APHA-AWWA-WEF dan Nilai SI hasil perhitungan

\begin{tabular}{cccccccc}
\hline Nama Waduk & Suhu $(\mathrm{T})$ & $\mathrm{pH}$ & Alkalinitas $\left(\mathrm{CaCO}_{3}\right)$ & $\mathrm{TDS}$ & $\mathrm{DHL}$ & $\mathrm{Kalsium}_{\left(\mathrm{Ca}^{2+}\right)}$ & $\mathrm{Nilai}$ SI \\
\hline Darma & 27,4 & 8,15 & 52,9 & 82 & 132,7 & 14,4 & $-0,2062$ \\
Bili-Bili & 29,5 & 7,29 & 53,0 & 76 & 122 & 12,7 & $-4,4672$ \\
Gajah Mungkur & 27,8 & 6,23 & 107 & 130 & 235 & 0,267 & $-3,5609$ \\
Manggar & 30,3 & 6,53 & 9,1 & 21 & 30,2 & 3,2 & $-3,1387$ \\
Batu Jai & 31,4 & 7,54 & 107 & 205 & 335 & 25,6 & $-0,2653$ \\
Karangkates & 29,6 & 8,80 & 126 & 217 & 317 & 0,063 & $-1,5938$ \\
Wonorejo & 30,5 & 8,70 & 58,5 & 87 & 134 & 0,040 & $-2,1389$ \\
Way Jepara & 29,0 & 7,80 & 60,0 & 71 & 103 & 13,6 & $-0,4915$ \\
Batu Tegi & 27,3 & 6,54 & 29,0 & 41 & 65,4 & 5,6 & $-2,446$ \\
\hline
\end{tabular}


Tabel 4. Data kualitas air untuk perhitungan tingkat korosivitas air terhadap infrastruktur sumber daya air berbahan semen menggunakan LSI A, B, C, D dan Nilai LSI hasil perhitungan

\begin{tabular}{ccccccc}
\hline Nama Waduk & Suhu $(\mathrm{T})$ & $\mathrm{pH}$ & Alkalinitas $\left(\mathrm{CaCO}_{3}\right)$ & TDS & $\begin{array}{c}\text { Kalsium } \\
\left(\mathrm{Ca}^{2+}\right)\end{array}$ & Nilai LSI \\
\hline Darma & 27,4 & 8,15 & 52,9 & 82 & 14,4 & $-0,40$ \\
Bili-Bili & 29,5 & 7,29 & 53,0 & 76 & 12,7 & $-1,2753$ \\
Gajah Mungkur & 27,8 & 6,23 & 107 & 130 & 0,267 & $-2,52$ \\
Manggar & 30,3 & 6,53 & 9,1 & 21 & 3,2 & $-3,3279$ \\
Batu Jai & 31,4 & 7,54 & 107 & 205 & 25,6 & $-0,023$ \\
Karangkates & 29,6 & 8,80 & 126 & 217 & 0,063 & $-1,7369$ \\
Wonorejo & 30,5 & 8,70 & 58,5 & 87 & 0,040 & $-2,311$ \\
Way Jepara & 29,0 & 7,80 & 60,0 & 71 & 13,6 & $-0,69$ \\
Batu Tegi & 27,3 & 6,54 & 29,0 & 41 & 5,6 & $-2,66$ \\
\hline
\end{tabular}

Berikut adalah cara atau rekomendasi untuk mencegah dan mengendalikan korosi pada infrastruktur sumber daya air berbahan semen atau mortar dengan $\mathrm{fc}$ ' atau dengan nilai kuat tekan $\leq 30 \mathrm{MPa}$, diantaranya adalah dengan menggunakan bahan-bahan bermutu baik sesuai spesifikasi teknis. Ada 3 jenis semen yang telah dikembangkan secara komersil, yaitu:

(a) semen alam, termasuk kapur atau hydraulic lime,

(b) semen aluminium,

(c) semen portland.

Kemudian berdasarkan hasil kajian, diperoleh kesimpulan bahwa semen jenis portland pozzolan yang biasa disebut dengan Special Blended Cement (SBC), memiliki keunggulan teknologi dalam meningkatkan resistensi terhadap serangan kimia yang dapat menyebabkan korosi atau kerusakan pada material. Hal ini telah dibuktikan berdasarkan tes hasil uji kimia, hasil uji fisika dan hasil tes permeability. Bahan campuran semen, dalam hal ini Special Blended Cement (SBC) telah diatur sedemikian rupa sehingga tahan terhadap air laut, sulfat, dan kobalt. Hal ini sejalan karena air laut lebih besar potensinya untuk menghasilkan korosi atau kerusakan terhadap material (Badan Pengembangan Wilayah Surabaya-Madura, 2020).

\section{Kesimpulan}

Hasil perhitungan Langelier Saturation Index A, B, C, D menunjukkan bahwa tingkat korosivitas air di 9 (sembilan) waduk di Indonesia, berpotensi menimbulkan korosi. Sedangkan berdasarkan hasil perhitungan SI Standard Method, APHA-AWWA-WEF, tingkat korosivitas air juga berpotensi menghasilkan korosi terhadap infrastruktur sumber daya air berbahan semen atau mortar dengan fc' atau dengan nilai kuat tekan $\leq 30$ $\mathrm{MPa}$. Hasil perhitungan tingkat korosivitas ini merupakan suatu indikasi terburuk dalam suatu kurun waktu tertentu.

Penilaian akhir tingkat korosivitas air antara rumus SI dan LSI A, B, C, D, tidak ada perbedaan atau relatif sama, sehingga dalam penentuan tingkat korosivitas air, dapat menggunakan rumus LSI A, B, C, D atau SI dari Standard Method APHA-AWWA-WEF. Akan tetapi, disarankan untuk lebih menggunakan rumus SI dari Standard Method APHA-AWWA-WEF, karena parameter-parameter kualitas air yang diujikan lebih lengkap, sehingga hasil perhitungan tingkat korosivitas air menjadi lebih valid.
Rumus perhitungan SI dan LSI A, B, C, D, digunakan untuk menghitung tingkat korosivitas air terhadap infrastruktur sumber daya air berbahan semen atau mortar dengan fc' atau dengan nilai kuat tekan $\leq 30$ $\mathrm{MPa}$, sedangkan untuk menghitung tingkat korosivitas air terhadap infrastruktur sumber daya air berbahan logam dapat menggunakan rumus perhitungan LSI (Tchobanoglus dkk, 2003), dan untuk menentukan tingkat korosivitas air terhadap infrastruktur sumber daya air berbahan beton dengan fc' atau dengan nilai kuat tekan $\geq 30 \mathrm{MPa}$ dapat menggunakan metode atau standar nasional Jerman, Deutsches Institut fur Normung E.V (DIN) 4030 Tahun 2008 (Lestari dan Moelyo, 2018).

Selain pencemaran air yang dapat meningkatkan tingkat korosivitas air terhadap berbagai infrastruktur, kondisi sekitar waduk atau pencemaran lingkungan juga memiliki peranan yang penting dalam meningkatkan daya korosif air terhadap infrastruktur sumber daya air.

Berdasarkan hasil kajian diperoleh kesimpulan, rekomendasi pencegahan dan pengendalian korosi terhadap infrastruktur sumber daya air berbahan semen dapat menggunakan semen jenis portland pozzolan yang biasa disebut dengan Special Blended Cement (SBC), karena SBC lebih resisten terhadap bahan kimia yang dapat menyebabkan korosi atau kerusakan lain pada material.

\section{Daftar Pustaka}

Aribiyanto, M.A.A., Pemetaan Tingkat Kesadahan Air Sumur di Wilayah Surabaya Barat Berbasis Aplikasi Sistem Informasi Geografis (SIG). Skripsi, Fakultas Sains dan Teknologi, Universitas Airlangga, Surabaya, 2016.

Arsitur Studio, Pengertian Semen, Bahan Penyusun, Pabrikasi dan Kegunaannya. Arsitur Studio, https://www.arsitur.com/2019/05/pengertian-semenbahan-kegunaan.html (akses1 Desember 2020).

Badan Pengembangan Wilayah Surabaya-Madura. Special Blended Cement. BPWS, https://bpws.go.id/index.php?option=com_k2\&view=ite m\&id=208:special-blended-cement\&Itemid $=753$ (akses 1 Desember 2020).

Badan Standardisasi Nasional, SNI 6989.57:2008 Air dan Air Limbah - Bagian 57: Metoda Pengambilan 
Tingkat Korosivitas Air Terhadap Infrastruktur Sumber Daya Air Berbahan Semen atau Mortar dengan fc' $\leq 30$ MPa pada 9 Waduk di Indonesia

Contoh Air Permukaan. Jakarta: Badan Standardisasi Nasional, 2008.

Effendi, H., Telaah Kualitas Air Bagi Pengelolaan Sumber Daya dan Lingkungan Perairan. Yogyakarta: Kanisius, 2003.

Jalaluddin; Ishak; Rosmayuni, Efektifitas Inhibitor Ekstrak Tanin Kulit Kayu Akasia (Acacia mangium) Terhadap Laju Korosi Baja Lunak (ST. 37) dalam Media Asam Klorida. Jurnal Teknologi Kimia Unimal, 2017, 4(1), 89-99.

Kenny, J.D.; Kemp, P.J.; Morgan, D.A.; Randtke, S.J., Ray, W.R.; Srivastava, R.M.; Wang, L.K., 2330 Calcium Carbobate Saturation. Baird, R.B.; Eaton, A.D.; Rice, E.W. eds., Standard Method for the Examination of Water and Wastewater, 23 ${ }^{\text {rd }}$ Edition. Washington DC: American Public Health Association, 2017, pp.2-39-247.

Langelier, W.F., The Analitycal Control of Anticorrosion Water Treatment. Journal of American Water Works Association, 1936, 28(10), 1500-1521.

Lestari, D.S.; Moelyo, M., Rancangan Pedoman Penentuan Korosivitas Air Terhadap Infrastruktur Sumber Daya Air. Bandung: Kementerian PUPR, 2018.

Chaulk, M.; Gates, A., West Saint John-Corrosion Control Investigation Final Report. Nova Scotia: CBCL Limited, 2019.

Mulyono, T., Teknologi Beton. Yogyakarta: Andi Offset, 2003.
Prasetyadi, W.P., Pengaruh Penambahan Pozzolan Pada Ordinary Portland Cement Terhadap Kualitas Pozzolan Portland Cement. Skripsi, Teknik Kimia, Fakultas Teknik dan Sains, Universitas Muhammadiyah, Purwokerto, 2018.

Rinawati; Hidayat, D.; Suprianto, R.; Dewi, P.S., Penentuan Kandungan Zat Padat (Total Dissolve Solid dan Total Suspended Solid) di Perairan Teluk Lampung. Analytical and Environmental Chemistry, 2016, 1(1), 36-46.

Sigler; W.A.; Bauder, J. Applying Knowledge to Improve Water Quality. Regional Water Program, Maontana State University, Extension Water Quality Program: Departement of Land Resources and Environmental Sciences, 2009.

Susanti, I.T.; Sasongko, S.B.; Sudarno, Kualitas Air Waduk Manggar Sebagai Sumber Air Baku Kota Balikpapan. Prosiding Seminar Nasional Pengelolaan Sumber Daya Alam dan Lingkungan, Semarang, 11 September, 2012.

Tchobanoglus, G.; Burton, F.; Stensel, H.D., Wastewater Engineering Treatment and Reuse, Fourth Edition. New York: Mc Graw Hill, 2003.

Yousefi, Z.; Kazemi, F.; Mohammadpour, R.A., Assessment of Scale Formation and Corrosion of Drinking Water Supplies in Ilam City (Iran). Environmental Health Engineering and Management Journal, 2016, 3(2), 75-80. 